\title{
Detection of Phenylpropanoids in Citrus Leaves Produced in Response to Xanthomonas citri subsp. citri
}

\author{
Christopher M. Ference, ${ }^{1,2}$ John A. Manthey, ${ }^{1, \dagger}$ Jan A. Narciso, ${ }^{1}$ Jeffrey B. Jones, ${ }^{2}$ and Elizabeth A. Baldwin ${ }^{1}$ \\ ${ }^{1}$ United States Department of Agriculture-Agricultural Research Service, U.S. Horticultural Research Laboratory, Ft. Pierce, FL 34945 \\ 2 University of Florida, Department of Plant Pathology, Gainesville, FL \\ Accepted for publication 7 November 2019.
}

\begin{abstract}
Citrus canker (CC), caused by the bacterial pathogen Xanthomonas citri subsp. citri, impacts citrus production in many areas of the world by reducing yields, degrading tree health, and severely blemishing the outer peels of fresh fruit. The relative susceptibility to $\mathrm{CC}$ among different species of Citrus varies from the highly susceptible lime (Citrus $\times$ aurantifolia), sweet orange $(C . \times$ sinensis $)$, and grapefruit $(C . \times$ paradisi $)$ to the much less susceptible calamondin $(C . \times$ microcarpa $)$ and kumquat (C. japonica). This investigation compares the responses to infection with $X$. citri subsp. citri of these five genotypes with respect to phenylpropanoid compound profiles and relative increases or decreases of specific compounds postinoculation. In response to X. citri subsp. citri infection, all hosts possessed increased concentrations of phenylpropanoids in leaf

paniculata) did not. Several of the tested genotypes exhibited notably increased production of fluorescent phenylpropanoids, including umbelliferone, herniarin, auraptene, scoparone, and others. The profiles of these compounds and their levels of production varied among the tested species yet all investigated Citrus genotypes exhibited increased concentrations of phenylpropanoids regardless of their degree of susceptibility to X. citri subsp. citri. Kumquat and calamondin, the tested genotypes least susceptible to $X$. citri subsp. citri, also exhibited the highest levels of the dihydrochalcone $3^{\prime}, 5^{\prime}$-di- $C$-glucosyl phloretin, the aglycone portion of which, phloretin, is a known antibiotic, although levels of this compound were not affected by inoculation with $X$. citri subsp. citri.
\end{abstract} tissue, whereas the similarly treated nonhost orange jessamine (Murraya
Keywords: bacteriology, biochemistry and cell biology
Citrus canker (CC), first identified on herbarium samples collected in the early 1800 s, spread with the global expansion of citrus cultivation (Dopson 1964; Luthra and Sattar 1942; Schubert et al. 2001). The bacterial pathogen Xanthomonas citri subsp. citri responsible for $\mathrm{CC}$ is transmitted by wind and rain, and is manifested as a nonsystemic infection of brown, corky, erumpent lesions on citrus peels, stems, and leaves (Bock et al. 2005; Gottwald et al. 2007; Graham et al. 2004). The susceptibility to CC varies among different Citrus genotypes within the Rutaceae family and, in this present study, the phytochemical responses of the less susceptible kumquat and calamondin are compared with the highly susceptible lime, sweet orange, and grapefruit.

Previous studies have shown that susceptibility within the genus Citrus generally decreases with tissue maturity (Lee 1921). Mature tissues show less field susceptibility due to build-ups of epicuticular wax on leaf and fruit surfaces, and to the development of bark cambium on stems (Graham et al. 1992a). Preexisting lesions on mature fruit show a diminishing ability to generate viable $X$. citri subsp. citri as the fruit senesces and the lesions age (Gottwald et al.

†Corresponding author: J. A. Manthey; john.manthey@usda.gov

This article is a U.S. Government work and is in the public domain in the United States. Mention of a trademark or proprietary product is for identification only and does not imply a guarantee or warranty the product by the United States Department of Agriculture (USDA). The USDA prohibits discrimination in all its programs and activities on the basis of race, color, national origin, gender, religion, age, disability, political beliefs, sexual orientation, and marital or family status.

Funding: Facilities and funding were supplied by the United States Department of Agriculture-Agricultural Research Service, United States Horticultural Research Laboratory, Fort Fierce, FL, U.S.A.

The author(s) declare no conflict of interest.

This article is in the public domain and not copyrightable. It may be freely reprinted with customary crediting of the source. The American Phytopathological Society, 2020.
2009). Immature fruit, for which stomates are not fully open, also seem to be less susceptible than mature fruit (Graham et al. 1992a,b; Lee 1918, 1921); thus, it appears that the ease of the pathogen's access to leaf mesophyll via open stomates is a leading factor influencing citrus field susceptibility.

However, this observation does not fully explain other differences that occur during the development of this disease, nor does it fully explain the dramatically different in planta bacterial populations that occur in the cankers of different Citrus genotypes following direct artificial inoculation (Ference et al. 2019; Wang et al. 2011). Previously, methods used for leaf inoculation resulted in damage which likely induced the formation of defense-related compounds regardless of the presence of inoculum (Treutter 2006). However, with the recent development of an inoculation method that minimizes tissue damage, the induction of chemical responses to plant physical damage is avoided and the study of plant responses to infections is possible (Francis et al. 2011; Gottwald and Graham 1992). Symptom development of CC and in planta populations of $X$. citri subsp. citri following this artificial inoculation exhibit a wide range of host responses, from faint chlorosis and small and sparse canker lesions and necrotic tissue to high concentrations of inoculum-producing lesions and massive tissue damage (Ference et al. 2019).

Many Citrus genotypes produce numerous different phenylpropanoids in response to stress, disease, and tissue damage (del Rio et al. 2004; Lattanzio et al. 2006; Manthey and Narciso 2013; Treutter 2006). Sweet orange has been shown to accumulate certain flavonoids in leaf tissue after exposure to Phytophthora citrophthora (del Rio et al. 2004), as well as highly fluorescent coumarins following $X$. citri subsp. citri inoculation (Manthey and Narciso 2013). Citrus varieties such as calamondin and kumquat may also possess phenylpropanoids in their peel which have antimicrobial activity, and it has been proposed that these varieties produce flavonoids in response to $X$. citri subsp. citri infection (Chen et al. 2012); however, this has yet to be firmly established and the specific compounds are not yet identified. The purpose of this study was to 
compare the different profiles of phenylpropanoids in methanol extracts of $X$. citri subsp. citri-inoculated and water-injected (control) leaves in five Citrus spp. along with similarly treated leaves of Murraya paniculata, a sixth genotype in the Rutaceae family and a nonhost of $X$. citri subsp. citri. Emphasis was placed on the detection of newly produced fluorescent coumarins and psoralens, similar to many previously reported compounds in citrus (Stanley and Vannier 1957; Tatum and Berry 1979). Additional analyses were made of other nonfluorescent phenylpropanoids, mainly flavonoids, in the control and $X$. citri subsp. citri-inoculated leaf tissues, some of which have been previously shown to exhibit antimicrobial effects.

\section{MATERIALS AND METHODS}

Plants. Six different genotypes of the family Rutaceae were selected as test plants covering a range of relative susceptibility from nonhost to highly susceptible hosts to X. citri subsp. citri. Among the six genotypes tested, five were in the genus Citrus. The six different genotypes included 20 seedlings each of orange jessamine (M. paniculata (L.) Jack), calamondin (Citrus $\times$ microcarpa Mabberley), Ridge Pineapple sweet orange $(C . \times$ sinensis $(\mathrm{L})$. Osbeck.), Duncan grapefruit (C. × paradisi Macfad.), Key lime (C. $\times$ aurantifolia (Christm.) Swingle), and 20 scions of Meiwa kumquat (C. japonica Thunb.) grafted on Cleopatra mandarin (C. reshni) rootstock. Each group of plants was divided evenly, with half injected with sterile water and half inoculated with $X$. citri subsp. citri. Plants were cultivated in pots in a quarantined greenhouse at the United States Department of Agriculture, Horticultural Research Laboratory in Ft. Pierce, FL, U.S.A. At the time of the experiment, plants were 1 to 2 years old and between 15 and $45 \mathrm{~cm}$ in height. Plants were pruned to synchronize flush, and fertigated daily with Peters Professional 20-10-20 General Purpose fertilizer (Everris, Dublin, OH, U.S.A.) dissolved at nitrogen at $325 \mathrm{ppm}$.

Bacterial strains. $X$. citri subsp. citri strain A306 was obtained from the Plant Pathology Department of the University of Florida (originally isolated in Brazil) and was cultured on nutrient agar (Becton, Dickinson and Co., Sparks, MD, U.S.A.) for $24 \mathrm{~h}$ at $31^{\circ} \mathrm{C}$. Bacteria were scraped from the surface of the agar plates with a disposable $10-\mu \mathrm{l}$ inoculating loop and deposited into a bottle containing $50 \mathrm{ml}$ of sterile deionized water. The bacterial suspension was visually measured using the McFarland Equivalence Turbidity Standards (Remel, Lenaxa, KS, U.S.A.), adjusted to a final concentration of approximately $3 \times 10^{8} \mathrm{CFU} \mathrm{ml}{ }^{-1}$, and subsequently verified by plating.

Inoculum was supplied via a $10-\mathrm{ml}$ sterile syringe inserted into a pulse injection apparatus (Pulse NeedleFree Systems, Inc., Lenexa, KS, U.S.A.) in a manner similar to previous experimentation (Francis et al. 2011), with a modified device and with the following differences in application. The device was set to deliver a $0.1-\mathrm{ml}$ injection volume at $40 \mathrm{psi}$ of compressed $\mathrm{CO}_{2}$. The pulse injection system's injection aperture was placed in contact with the target leaf's abaxial surface, with a hard rubber backstop held firmly against the adaxial surface directly opposite the injection aperture. Two leaves of similar maturity on each of 10 plants received a single air-pulse injection. Leaves of control plants were injected with only sterile deionized water in an identical manner. One leaf per plant would later be removed at 14 days and the other at 21 days postinoculation (DPI).

Leaf sample preparation. Leaves were detached for tissue collection at 14 and 21 DPI from each of 10 plants per genotype. These two sampling points were based on preliminary experiments which showed little in the way of accumulation of detectable fluorescent compounds in calamondin and grapefruit within the first 2 weeks after inoculation of $X$. citri subsp. citri (data not shown). Three discs of leaf tissue were removed from around the inoculation site for each leaf using a stainless steel cork borer (10-mm internal diameter [i.d.]). Each disc contained approximately two parts symptomless tissue and one part CC symptomatic tissue. Each of the three discs was placed into one of three $25-\mathrm{ml}$ glass vials. Finally, for each genotype or sampling period (14 or $21 \mathrm{DPI}$ ), there were three vials, each containing 10 discs of leaf tissue, with 1 leaf disc from each of the 10 different trees within that genotype group. These vials were immediately filled with $10 \mathrm{ml}$ of methanol, sealed, protected from light, and placed on an orbital shaker at $100 \mathrm{rpm}$ for $24 \mathrm{~h}$. After $24 \mathrm{~h}$, the methanol from each vial was removed and placed in a second vial. The original vials with the leaf discs were refilled with another $10 \mathrm{ml}$ of methanol and shaken for an additional $24 \mathrm{~h}$. The two 10-ml methanol samples for each set of leaf discs were combined and were reduced under vacuum to dryness. Methanol $(0.40 \mathrm{ml})$ was added to dissolve the dried solids, then transferred to an autosample vial for high-performance liquid chromatography (HPLC) photodiode array mass spectrometry (PDA-MS) and HPLC-fluorescence analysis.

Compound identification. Compound profiles were analyzed by HPLC-fluorescence detection using a Varian HPLC with ProStar 210 pumps and a ProStar 410 autosampler controlled by Star software (ver. 6.41; Varian, Walnut Creek, CA, U.S.A.). Compound separations were achieved with a Waters XBridge C8 column (4.6× $150 \mathrm{~mm}$ i.d.) (Waters, Milford, MA, U.S.A.). Elution conditions included gradients of aqueous $0.5 \%$ formic acid/acetonitrile, initially composed of $(90 / 10, \mathrm{vol} / \mathrm{vol})$, and changed in compositions in linear gradients to $80 / 20,75 / 25,60 / 40,30 / 70,30 / 70,90 / 10$, and $90 / 10$ ( vol/vol) by $10,15,23,40,45,53$, and $60 \mathrm{~min}$, respectively, at

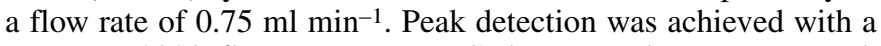
Jasco FP-2020 fluorescence HPLC detector. Fluorescence peak detection occurred at an emission wavelength of $335 \mathrm{~nm}$, with an excitation wavelength of $400 \mathrm{~nm}$. Fluorescence data were recorded and processed with ChromNAV (Jasco, Tokyo, Japan).

Further compound identification was done through matching molecular weights measured by a Waters ZQ mass spectrometer, and by observing exact peak overlaps with commercial standards. Verification was achieved by matching the fluorescence emission spectra of the leaf compounds with those of commercial standards. Commercial standards included bergamottin (5-geranyloxypsoralen) and herniarin (7-methoxycoumarin) (Indofine Chemical Company, Inc., Hillsborough, NJ, U.S.A.), limettin (5,7-dimethoxycoumarin) (Fluka Analytical, Steinheim, Germany), scopolin (scopoletin 7-Oglucoside) (TargetMol, Boston, MA, U.S.A.), scopoletin (6-methoxyumbelliferone) and scoparone (6,7-dimethoxycoumarin) (Aldrich Fine Chemicals, Milwaukee, WI, U.S.A.), and umbelliferone (7hydroxycoumarin) (Sigma-Aldrich, St. Louis, MO, U.S.A.).

Determination of limits of detection and quantitation. The limit of detection (LoD) and limit of quantitation (LoQ) were determined by calculating the mean instrument response value (microvolts) of 25 samples without analyte at the retention times corresponding to the identified fluorescent compounds, using the following formulas (Aldeek et al. 2015; Armbruster and Pry 2008): $\mathrm{LoD}=$ mean $_{\text {blank }}+3\left(\mathrm{SD}_{\text {blank }}\right)$ and $\mathrm{LoQ}=$ mean $_{\text {blank }}+10\left(\mathrm{SD}_{\text {blank }}\right)$.

Known concentrations of commercial standards of eight compounds were run using the HPLC, column, fluorescent detector, and elution gradient as described above. LoD and LoQ concentrations (milligrams per liter) of compounds were determined via linear regression equations formulated to resolve the relationship between concentration (milligrams per liter) and fluorescent peak intensity (microvolts) (Table 1).

Statistical analysis. Maximum peak intensity heights from the fluorescence data collected on ChromNAV were input into the JMP statistical suite (version 11.2.0; SAS Institute, Cary, NC, U.S.A.). Data were evaluated using analysis of variance and, subsequently, Tukey's honestly significant difference test. The significance was defined at $P<0.05$ (Table 2).

\section{RESULTS}

Each of the Citrus genotypes examined in this study exhibited physical and chemical evidence of disease in the leaves inoculated 
with $X$. citri subsp. citri. The physical appearances of the canker lesions at 21 DPI are shown in Figure 1, and are similar to those published previously (Ference et al. 2019). Leaf surfaces of the less susceptible kumquat and calamondin exhibited lesions with far less total tissue damage compared with the highly susceptible grapefruit, lime, and sweet orange while, for the highly susceptible genotypes, both sides of the leaves showed extensive tissue damage. As anticipated, there were no lesions on the inoculated leaves of orange jessamine, nonhost to $X$. citri subsp. citri. Phytochemical analyses of the five Citrus spp. were run to gain further information about the chemical changes that occur in response to $X$. citri subsp. citri infection. To conduct these analyses, methanol extracts of $X$. citri subsp. citri-inoculated and water-injected leaf tissues of each species were examined by HPLC-UV-MS as well as by HPLCfluorescence detection, which provides highly sensitive and selective detections of fluorescent coumarins and psoralens.

Calamondin. The HPLC-fluorescence chromatograms of extracts of $X$. citri subsp. citri-inoculated calamondin leaves

TABLE 1. Limit of detection (LoD), limit of quantitation (LoQ), and linear relation of eight fluorescent compounds

\begin{tabular}{|c|c|c|c|c|}
\hline Compound & $\begin{array}{c}\text { LoD } \\
\text { (mg/liter) }\end{array}$ & $\begin{array}{c}\text { LoQ } \\
\text { (mg/liter) }\end{array}$ & $\begin{array}{c}\text { Regression equation } \\
\text { (concentration-peak area) }\end{array}$ & $\begin{array}{l}\text { Correlation } \\
\text { coefficient }\end{array}$ \\
\hline Tryptophan & 837.80 & $4,364.98$ & $y=0.13 x+140.32$ & 0.9088 \\
\hline Scopoletin & 0.05 & 0.08 & $y=11342.37 x-308.33$ & 1 \\
\hline Umbelliferone & 0.15 & 0.49 & $y=3820.47 x+182.78$ & 1 \\
\hline Scoparone & 0.11 & 0.31 & $y=21452.65 x-257.22$ & 1 \\
\hline Herniarin & 0.10 & 0.19 & $y=32126.81 x-1953.61$ & 0.9998 \\
\hline Limettin & 0.02 & 0.05 & $y=30329.41 x-46.56$ & 1 \\
\hline Auraptene & 0.03 & 0.05 & $y=9761.88 x+826.83$ & 0.9998 \\
\hline Bergamottin & 24.99 & 132.99 & $y=6.74 x+285.61$ & 0.9976 \\
\hline
\end{tabular}

TABLE 2. Mean values of fluorescence intensity units of fluorescent compounds in Xanthomonas citri subsp. citri-inoculated and control leaves from five different Citrus plants ${ }^{\mathrm{z}}$

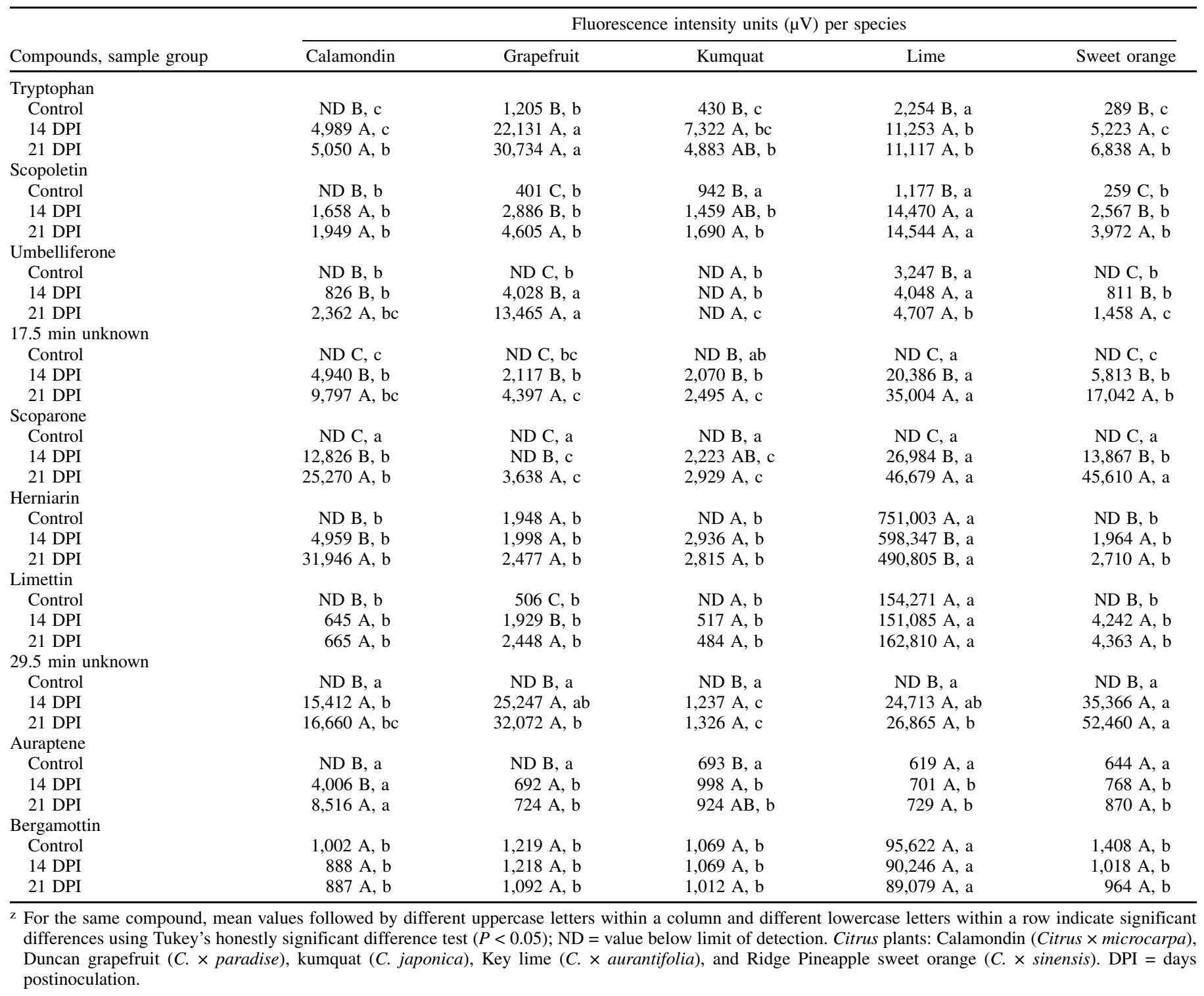


exhibited multiple fluorescent peaks not present, or present at only trace amounts, in the water-injected leaves (Table 2; Fig. 2). In these chromatograms, major peaks occurred at $18.5 \mathrm{~min}$ for scoparone, $23.0 \mathrm{~min}$ for herniarin (7-methoxycoumarin), $39.5 \mathrm{~min}$ for auraptene (7-geranyloxycoumarin), and two unknown compounds at 17.5 and $29.5 \mathrm{~min}$ (Fig. 2). Smaller peaks appeared in the extracts of the $X$. citri subsp. citri-inoculated calamondin leaves for tryptophan, scopolin (scopoletin-7-O-glucoside), scopoletin, and umbelliferone at 6.1, 6.7, 11.5, and $14.0 \mathrm{~min}$, respectively. In sharp contrast, umbelliferone, tryptophan, herniarin, auraptene, scoparone, and the unknowns occurred below the LoD in control samples (Table 2). The fluorescent peak intensities for tryptophan, scopoletin, umbelliferone, scoparone, and the 17.5- and 29.5-min unknowns were significantly higher in $X$. citri subsp. citriinoculated leaves at 14 DPI than in water-injected controls (Table 2; Fig. 2). Herniarin and auraptene were significantly higher in X. citri subsp. citri-inoculated leaves at at 21 DPI than in waterinjected controls (Table 2; Fig. 2). Umbelliferone, scoparone, herniarin, and auraptene peaks increased in intensity in the $X$. citri subsp. citri-inoculated leaves during the period between 14 and 21 DPI (Table 2; Fig. 2).

Analysis of calamondin leaf extracts showed the occurrence of a large number of minor-occurring flavone glycosides as well as phloretin-di- $C$-glucoside at $13.2 \mathrm{~min}$, all of which were unaffected by inoculation with $X$. citri subsp. citri (Fig. 3). Sinensetin, nobiletin, tetramethoxyscutellarein, and tangeretin were detected, as well as other minor polymethoxylated flavones (PMFs) (data not shown). In addition to these compounds, there were also three fluorescent lipophilic unknown compounds with similarly unique UV spectra (Fig. 4). These compounds were detected only in the calamondin leaf extracts and showed no differences in amounts between water-injected control and $X$. citri subsp. citri-inoculated samples and, thus, did not appear to be part of a response of calamondin to $X$. citri subsp. citri infection.

Kumquat. Extracts of $X$. citri subsp. citri-inoculated kumquat leaves produced low-intensity peaks (compared with the newly formed peaks in the other citrus varieties) at 6.8, 6.9, 11.5, 17.5, 18.5, 29.5, and $39.5 \mathrm{~min}$ (Fig. 5A). In X. citri subsp. citri-inoculated kumquat leaves, tryptophan (6.8 min), scopolin (6.9 min), scopoletin (11.5 min), scoparone (18.5), auraptene (39.5 min), and the two unknown compounds similarly detected in calamondin at 17.5 and 29.5 min were all induced by $X$. citri subsp. citri inoculation (Table 2). In the control leaves, the peaks due to herniarin, limettin, scoparone, and the unknowns at 17.5 and $29.5 \mathrm{~min}$ were below the LoD values for these compounds. Tryptophan, auraptene, and the unknown at 29.5 min were significantly higher in $X$. citri subsp. citri-inoculated leaves at 14 DPI than in water-injected controls (Table 2). Scopoletin, scoparone, and the unknown at $17.5 \mathrm{~min}$ significantly increased in concentration during the period from 14 to $21 \mathrm{DPI}$, and were significantly higher in X. citri subsp. citriinoculated leaves at 21 DPI than in control leaves (Table 2). In in the water-injected and $X$. citri subsp. citri-inoculated leaves, very similar profiles of phloretin $3^{\prime}, 5^{\prime}$-di- $C$-glucoside (13.2 min), isomargaretin (14.9 $\mathrm{min})$, sinapinic acid glucoside (15.1 $\mathrm{min}$ ), calamondin
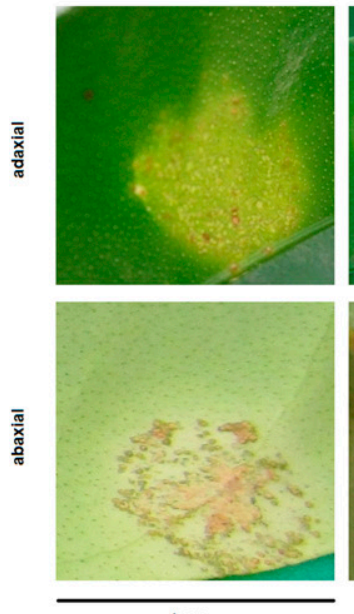

$1 \mathrm{~cm}$
Meiwa kumquat
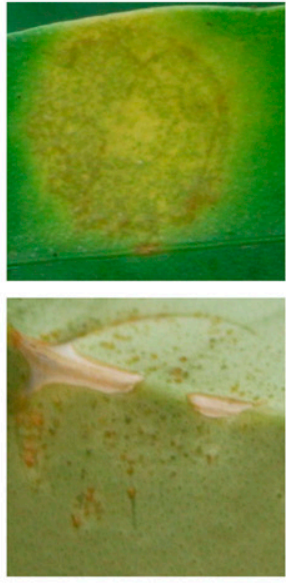

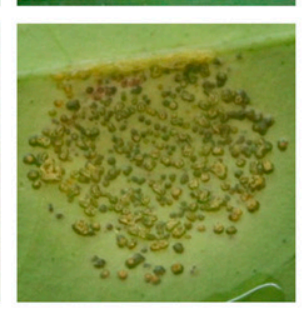

Key lime

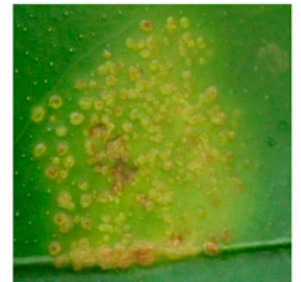

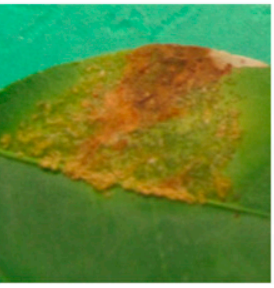

Ridge Pineapple sweet orange
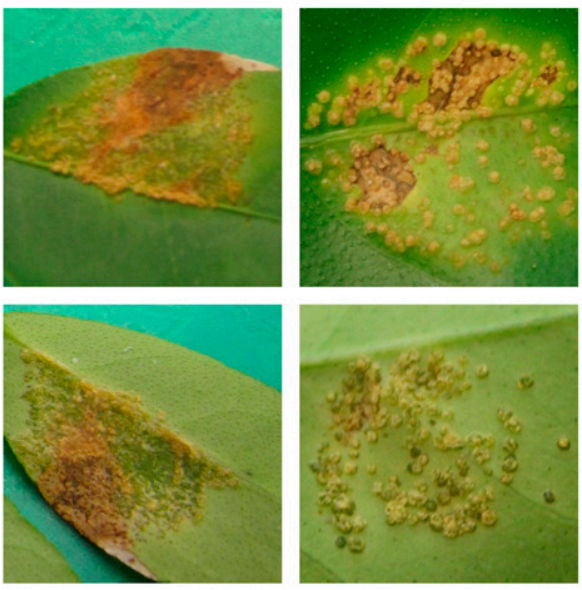

orange jessamine
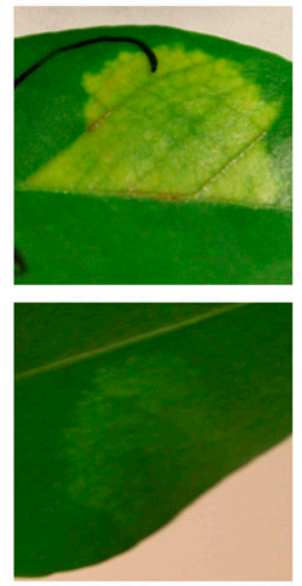

Fig. 1. Physical appearances of the canker lesions at 21 days postinoculation on leaves of the five Citrus hosts and the nonhost orange jessamine.
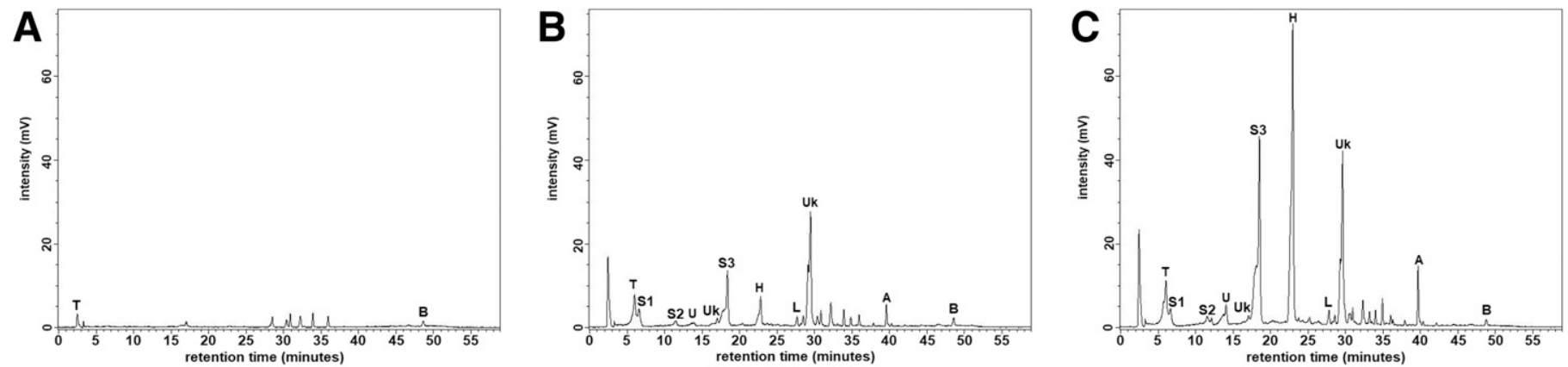

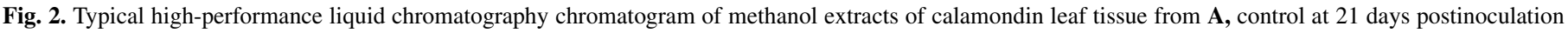

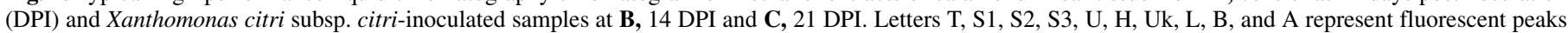

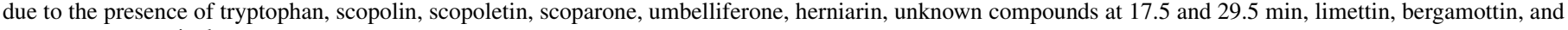
auraptene, respectively. 
fortunellin-glucoside (16.2 min), margaretin (17.2 $\mathrm{min})$, and fortunellin (20.2 $\mathrm{min}$ ) were observed (data not shown).

Grapefruit. Extracts of $X$. citri subsp. citri-inoculated grapefruit leaves showed intense fluorescence peaks at 6.9, 11.5, 13.5, $17.5,18.5,27.5,29.5,32.3,35.5,39.5,45.0$, and $44.8 \mathrm{~min}$ at 14 and 21 DPI (Table 2; Fig. 5B). The identified peaks represent tryptophan/scopolin (overlapping) (6.9 min), scopoletin (11.5 min), umbelliferone (13.5 min), scoparone (18.5 min), limettin
(27.5 $\mathrm{min}$ ), auraptene (39.5 min), and the two unknowns observed in calamondin at 17.5 and $29.5 \mathrm{~min}$. Peaks due to umbelliferone, auraptene, scoparone, and the unknowns at 17.5 and $29.5 \mathrm{~min}$ were below the LoD in control samples. Tryptophan, scopoletin, umbelliferone, scoparone, limettin, auraptene, and the two unknowns at 17.5 and $29.5 \mathrm{~min}$ were significantly higher in $X$. citri subsp. citri-inoculated leaves at 14 DPI than in waterinjected controls (Table 2). Fluorescent peaks due to umbelliferone,

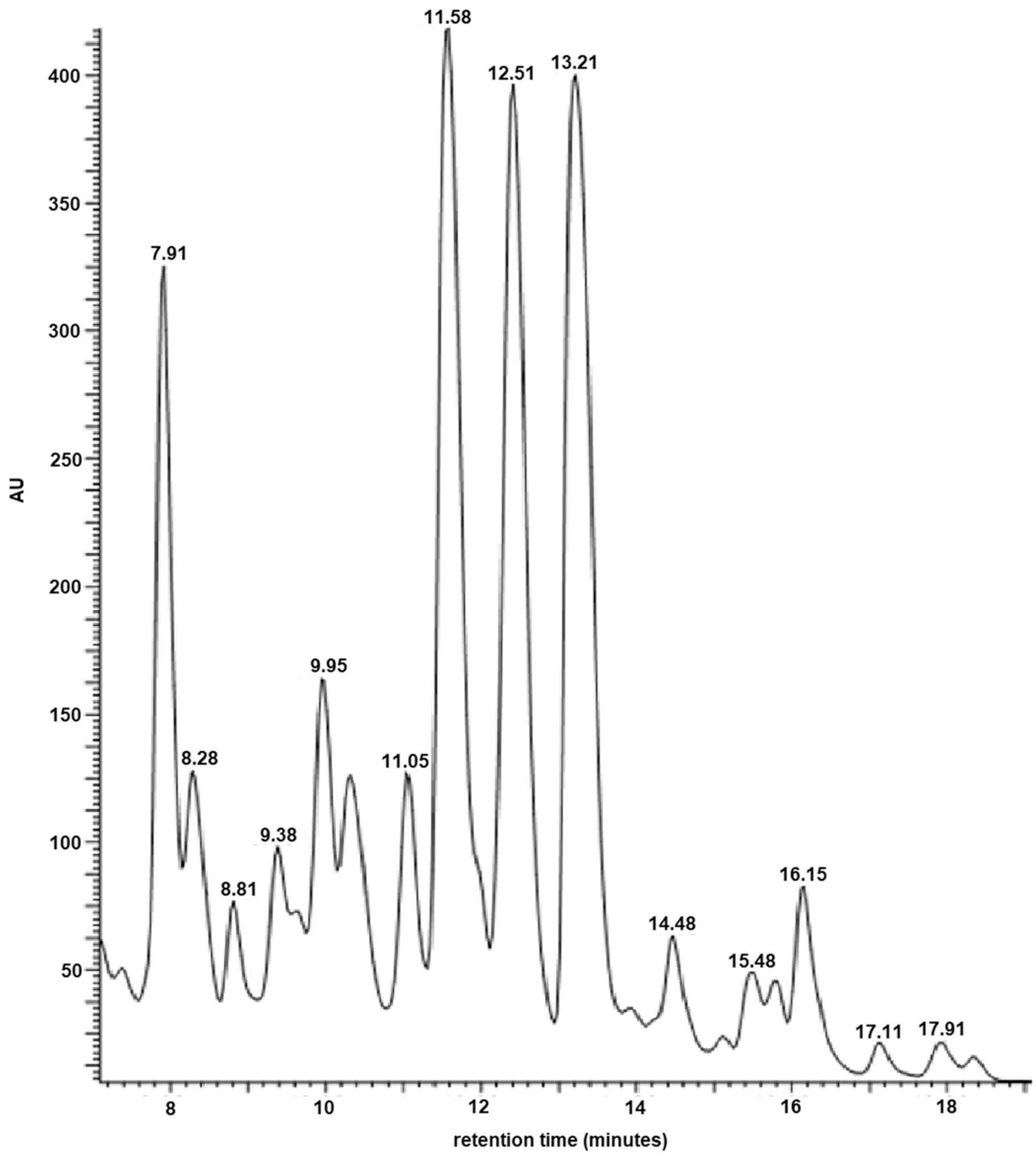

Fig. 3. High-performance liquid chromatography chromatogram of calamondin leaf extracts. Peaks with retention times of 7.91, 8.28, 9.95, 11.05, 11.58, and 12.51 min exhibited mass spectra indicative of flavone-C-glycosides. The peak at 13.21 min was identified as $3^{\prime}, 5^{\prime}$-di-C-glucosylphloretin. Peaks at 15.48 (diosmin), 16.15 , and 17.11 (neohesperidin) min exhibited mass spectra indicative of flavonoid- $O$-glycosides. 
scopoletin, scoparone, limettin, and the unknown at $17.5 \mathrm{~min}$ further increased in intensity in the $X$. citri subsp. citri-inoculated leaves during the period between 14 and 21 DPI (Table 2). HPLCMS analysis of the leaf extracts showed low concentrations of the PMFs sinensetin, nobiletin (26.9 min) (Fig. 5B), tetramethylscutellarein, and tangeretin, (data not shown). The same concentrations of these compounds occurred in the X. citri subsp. citri-inoculated and the control water-injected leaves. Large fluorescent peaks at retention times $26.9 \mathrm{~min}$ (nobiletin), 32.4 (unknown), $36.0 \mathrm{~min}$ (6',7'-epoxybergamottin), and $45.0 \mathrm{~min}$ (unknown) occurred regardless of the inoculation treatment. Additional analyses of the flavonoids in grapefruit leaves showed evidence of naringin, rhoifolin, and other flavone glycosides, as reported previously (Manthey et al. 2000).
Lime. Extracts of $X$. citri subsp. citri-inoculated lime leaves at 21 DPI exhibited intense fluorescent peaks at $6.1 \mathrm{~min}$ (tryptophan), $11.5 \mathrm{~min}$ (scopoletin), $17.5 \mathrm{~min}$ (unknown), $18.5 \mathrm{~min}$ (scoparone), $23.0 \mathrm{~min}$ (herniarin), $27.4 \mathrm{~min}$ (limettin), $29.5 \mathrm{~min}$ (unknown), $42.0 \mathrm{~min}$ (unknown), and $47.0 \mathrm{~min}$ (bergamottin) (Table 2; Fig. 5C). Although the peak associated with herniarin occurred in both waterinjected control and $X$. citri subsp. citri-inoculated lime leaves, this peak was 26 to $53 \%$ higher in the control leaves (Table 2). The other substantial fluorescent peaks in the lime leaf extracts were identified as limettin (27.4 min) and bergamottin (47.0 min) (Fig. $5 \mathrm{C})$. The presence and relative intensities of the limettin and bergamottin fluorescence peaks were independent of $X$. citri subsp. citri infection (Table 2). The peaks at 17.5 and $29.5 \mathrm{~min}$ were similar to the unknown compounds detected in $X$. citri subsp.

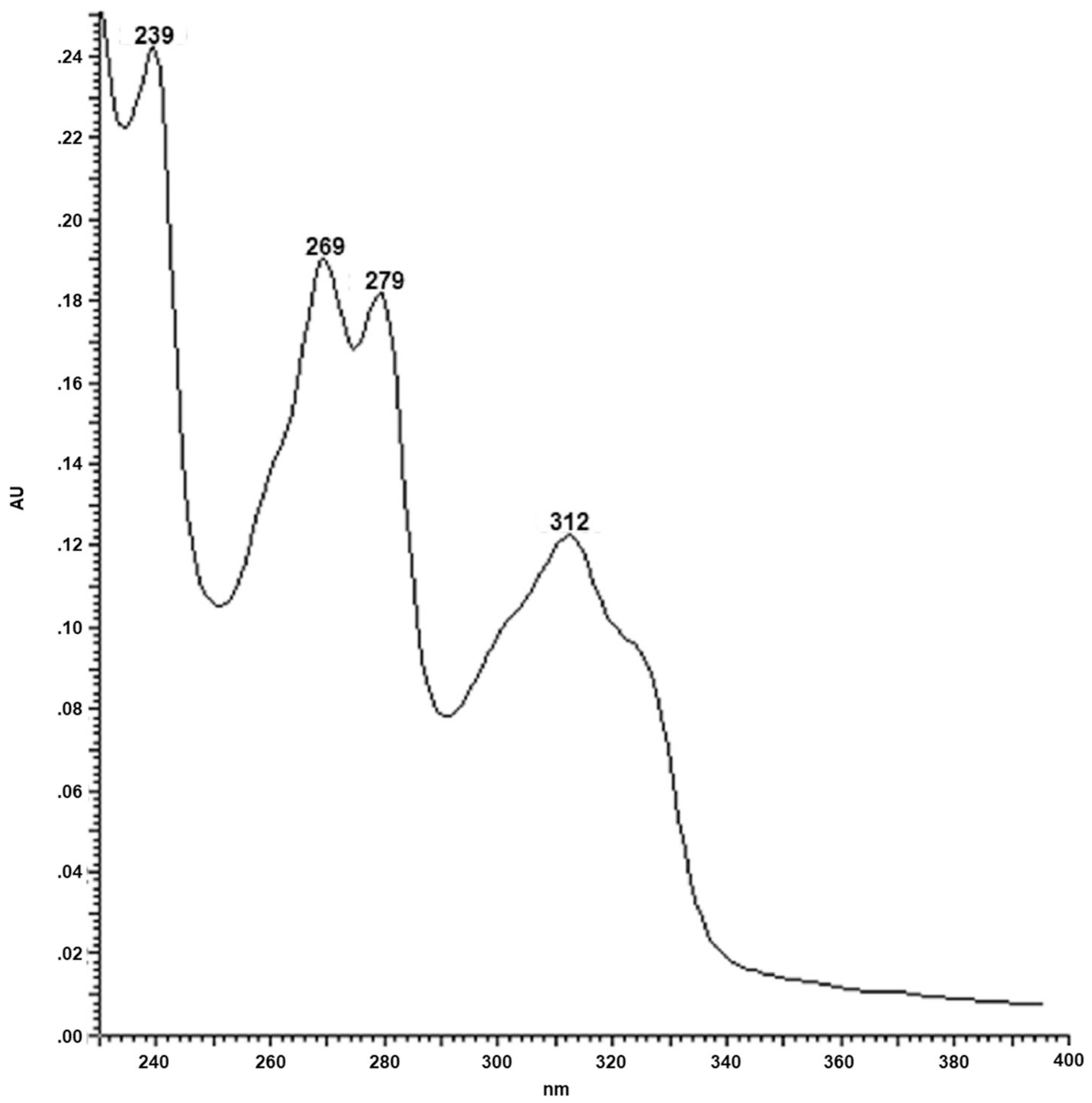

Fig. 4. UV spectra from the high-performance liquid chromatography chromatogram of one of the N-containing unknown compounds in calamondin leaves. Two other compounds with similar UV spectra also occur in these leaf extracts. 
citri-inoculated leaves from all other tested citrus genotypes. Peaks due to scoparone and the unknown at $29.5 \mathrm{~min}$ were below the LoD in control samples. Tryptophan, scopoletin, umbelliferone, scoparone, and the two unknowns at 17.5 and 29.5 min were significantly higher in 14 DPI $X$. citri subsp. citri-inoculated leaves than in waterinjected controls (Table 2). Scoparone and the unknown at $17.5 \mathrm{~min}$ further increased in intensity in the $X$. citri subsp. citri-inoculated leaves during the period between 14 and 21 DPI (Table 2). Herniarin was significantly lower in $X$. citri subsp. citri-inoculated leaves at 14 and 21 DPI than in the control leaves (Table 2). From 14 to 21 DPI, the average peak intensity in the extracts of $X$. citri subsp. citriinoculated leaves associated with scoparone showed a $58 \%$ increase, whereas those for tryptophan, scopolin, scopoletin, herniarin, umbelliferone, limettin, bergamottin, and the unknown compound detected at 29.5 min were unchanged (Table 2).

The chemical composition of the lime leaf extracts were further analyzed with HPLC-PDA-MS. These analyses showed numerous coumarins and psoralens. Compounds identified by UV and MS analysis included, in part, tryptophan, vicinen-2, diosmin, hesperidin, $p$-coumaric acid, herniarin, angelicin, bergapten, limettin, isopimpinellin, xanthotoxol geranyloxy ester, and bergamottin. Based on the observations made with the control and X. citri subsp. citri-inoculated leaf samples, very little change occurred in the levels of these phenylpropanoids in response to infection with $X$. citri subsp. citri.
Sweet orange. HPLC chromatograms of the extracts of sweet orange leaves inoculated with $X$. citri subsp. citri showed fluorescent peaks at $6.1,6.7,11.5,17.5,18.5,21.0,23.5,29.5$, $32.5,35.5,38.5$, and $40.1 \mathrm{~min}$. Major peaks identified were 6.1 (tryptophan), 6.7 (scopolin), 11.5 (scopoletin), 17.5 (unknown), 18.5 (scoparone), and 29.5 (unknown) min (Fig. 5D). Minor peaks at 14.0 (umbelliferone), 22.5 (herniarin), and 27.4 (limettin) min were also detected. Peaks due to umbelliferone, herniarin, limettin, scoparone, and the unknowns at 17.5 and $29.5 \mathrm{~min}$ were below the LoD in control samples. Tryptophan, scopoletin, umbelliferone, scoparone, herniarin, limettin, and the two unknowns at 17.5 and 29.5 were significantly higher in $X$. citri subsp. citri-inoculated leaves at 14 DPI than in water-injected controls (Table 2). Scopoletin, umbelliferone, and scoparone further increased in intensity in the $X$. citri subsp. citri-inoculated leaves during the period between 14 and 21 DPI (Table 2). An intense fluorescent peak for an unknown compound at 32.5 min was higher in control samples (data not shown).

Orange jessamine. No new production of fluorescent phenylpropanoids, as seen in other genotypes, occurred after $X$. citri subsp. citri inoculation. Additionally, the HPLC chromatograms monitored at 335 and $400 \mathrm{~nm}$ exhibited no differences between the control and X. citri subsp. citri-inoculated leaf extracts. Fluorescent peaks from inoculated and noninoculated orange jessamine leaf tissues showed no significant differences between the two groups
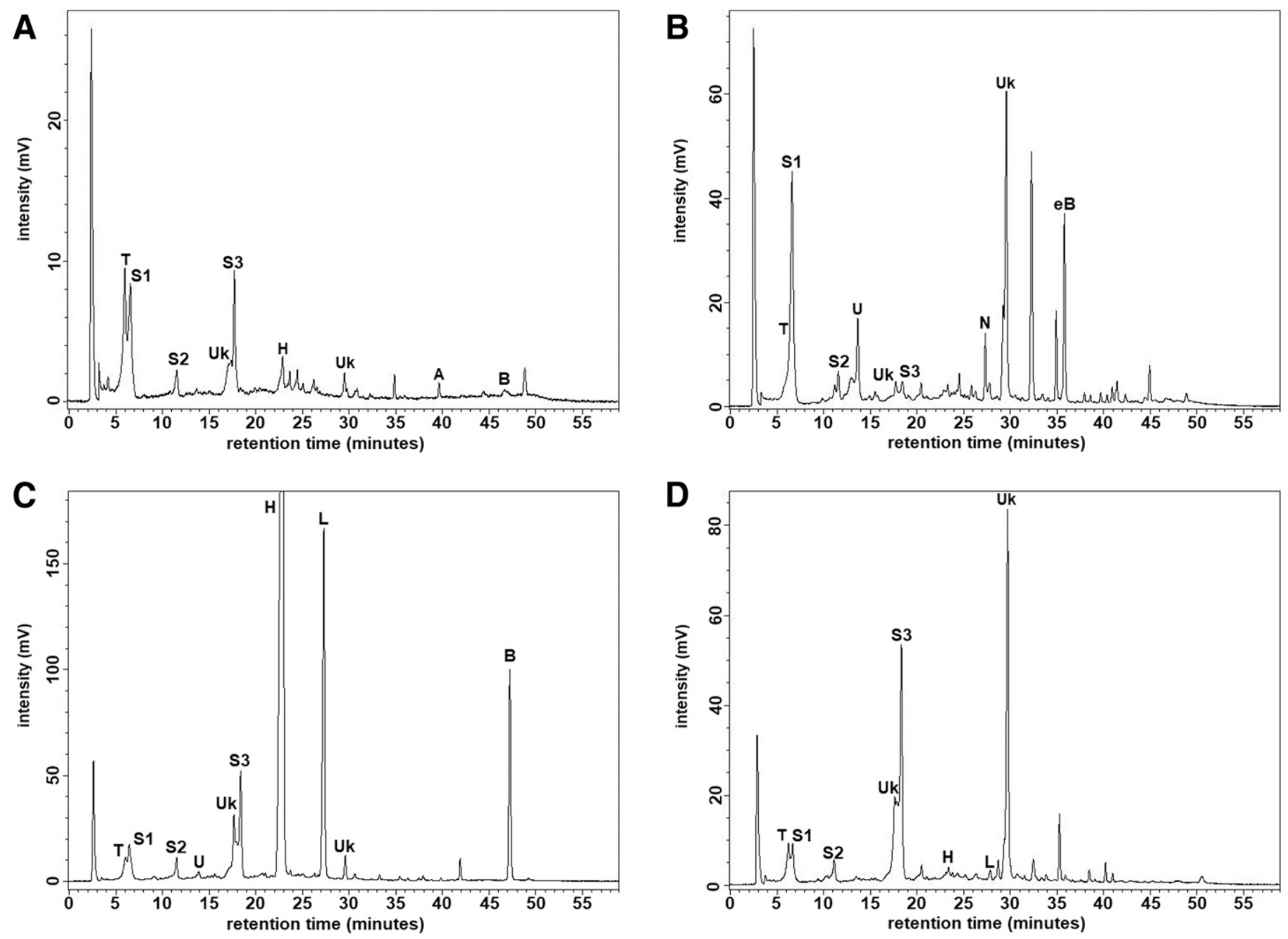

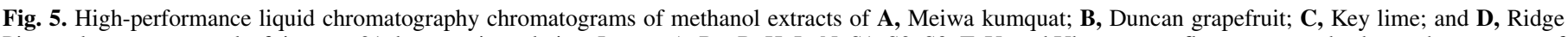

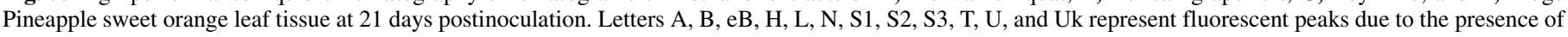

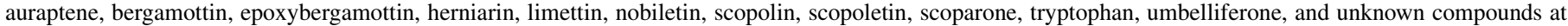
17.5 and $29.5 \mathrm{~min}$, respectively. 
(control and $X$. citri subsp. citri) or between the two sampling dates (14 and 21 DPI). Orange jessamine leaf tissue exhibited a number of intense fluorescent peaks at 2.9, 19.0, 21.0, 22.0, 28.4, 31.0, 37.5, 43.0 , and $45.5 \mathrm{~min}$, none of which corresponded to the intense fluorescent peaks noted in the other investigated genotypes (Table 2). A concurrent HPLC-UV analysis of the orange jessamine leaf extracts showed a preponderance of coumarins and earlyeluting hydoxycinnamates and a nearly complete absence of flavonoids. The fluorescent peaks at 19.0, 22.0, 28.4, 31.0, and $37.5 \mathrm{~min}$ exhibited coumarin-like UV spectra. The majority of coumarins thus far identified in orange jessamine are constructs of 5,7-dihydroxycoumarin with different isopentenyl-based substituents positioned at the coumarin C8 position (Aziz et al. 2010; Imai et al. 1989; Wu 1988). HPLC-MS of the above fluorescent peaks showed prominent $189 \mathrm{~m} / \mathrm{z}$ fragment ions consistent with the occurrence of the above-published 5,7-dihydroxycoumarin adducts (data not shown).

Compounds. Among extracts of water-injected control leaves, fluorescent peaks due to tryptophan, scopoletin, umbelliferone, herniarin, limettin, and bergamottin were all highest in lime samples (Table 2). Scoparone and the unknowns at 17.5 and 29.5 were below the LoD in the control leaves of all genotypes, including lime (Table 2). For $X$. citri subsp. citri-inoculated leaves at 14 and 21 DPI, fluorescent peaks due to scopoletin, umbelliferone, scoparone, herniarin, limettin, bergamottin, and the unknowns at 17.5 and $29.5 \mathrm{~min}$ were also highest among lime samples (Table 2).

Flourescent peaks due to umbelliferone, scoparone, herniarin, limettin, auraptene, and the unknowns at 17.5 and 29.5 min were below the LoD in water-injected control leaves from kumquat (Table 2). With the addition of tryptophan and scopoletin, these same compounds were all also below the LoD in water-injected leaves of calamondin (Table 2). Among control leaves, all genotypes had statistically similar values for peaks due to auraptene, with the values from both calamondin and kumquat being below the LoD (Table 2). However, the most intense fluorescent peak due to auraptene was seen in X. citri subsp. citriinoculated calamondin samples (Table 2).

\section{DISCUSSION}

Our results show that, with the exception of orange jessamine, all tested Rutaceae family genotypes accumulated phenylpropanoids in leaf tissue in response to inoculation with $X$. citri subsp. citri, and did so regardless of that specific genotype's relative susceptibility to CC (Table 2). Although orange jessamine, a member of the Rutaceae family, is a nonhost of $X$. citri subsp. citri, bacterial populations persist in its leaf tissue for more than 30 days after artificial inoculation (Ference et al. 2019). However, the fluorescent peaks produced by orange jessamine leaf tissue samples exhibited no differences between noninoculated and inoculated samples at either 14 or 21 DPI. The fluorescent peaks that are detected in orange jessamine samples are dissimilar to the fluorescent peaks from compounds found in $X$. citri subsp. citri-inoculated samples from the other investigated host genotypes. The absence of new production of phenylpropanoids in orange jessamine leaf tissue after inoculation with $X$. citri subsp. citri, combined with the absence of correlation between the chromatograms of $X$. citri subsp. citri-inoculated orange jessamine samples and of all other $X$. citri subsp. citri-inoculated genotypes (calamondin, kumquat, grapefruit, sweet orange, and lime), suggests that fluorescent peaks due to phenylpropanoids found in extracts of $X$. citri subsp. citri-inoculated Citrus leaves result from interactions between the bacterium and CC-susceptible hosts.

Phenylpropanoids produced by plants have many functions, and the involvement of phenylpropanoids and their derivatives in influencing plant-microbe interactions has been widely studied (Cueva et al. 2010; Daglia 2012; del Rio et al. 2004; Jagani et al. 2009; Joshi et al. 2015; Rauha et al. 2000). Plant phenolics can act as signals to attract beneficial or protect against harmful microorganisms (Treutter 2006). Some phenylpropanoids provide protection to the plant in adverse environmental conditions or after tissue damage, while others are defensive compounds which are either preformed or induced in response to injury, stress, or infection by pathogens (Treutter 2006). Studies on citrus report that increased tolerance to $\mathrm{CC}$ corresponded to higher total phenolic compound concentration in leaves (Jiao et al. 1992). PMFs have previously been found to occur in calamondin, and levels of PMFs and flavanones fluctuate as part of the defense response of Valencia sweet orange to P. citrophthora infection (del Rio et al. 2004; Gonçalves et al. 2018; Lou and Ho 2017; Tatum and Berry 1979). Total ethanol extracts from calamondin and kumquat peel, which contain high levels of the flavonoids diosmin and quercetin, were shown to inhibit $X$. citri subsp. citri growth in vitro (Chen et al. 2012). Numerous instances of in planta phenylpropanoid gene induction in response to tissue injury and infections have been reported in citrus (Chen et al. 2012; Ference 2016; Ortuño et al. 1997, 2011). Specifically, genes associated with phenylpropanoid biosynthesis and metabolic processes are significantly upregulated in kumquat, calamondin, and sweet orange after exposure to $X$. citri subsp. citri (Ference 2016; Fu et al. 2012; Khalaf et al. 2007, 2011).

The production of secondary metabolites, including phenylpropanoids, is a known and widely investigated phenomenon associated with the physiological response of citrus plants to biotic stress, and certain phenylpropanoids found in the tissues of citrus plants are known to be antimicrobial, including being inhibitory specifically toward $X$. citri subsp. citri. In alignment with this, Citrus plants in our study presented significantly altered chromatograms after inoculation with $X$. citri subsp. citri, indicative of the production and accumulation of specific phenylpropanoids in response to biotic stress.

The phloretin-di- $C$-glucoside found in calamondin leaf tissue is a $3^{\prime}, 5^{\prime}$-di-C-glucosyl phloretin and occurs at high concentrations in both calamondin and kumquat (Barreca et al. 2011; Lou and Ho 2017; Yu et al. 2013), the aglycone of which is the antibiotic phloretin (Barreca et al. 2014). The phloretin 3',5'-di- $C$-glucoside has been shown to occur at levels between 21.3 and $60.2 \mathrm{mg} / \mathrm{g}$ dry weight in the leaves of different kumquat varieties (Ogawa et al. 2001).

Calamondin is considered to be only mildly susceptible to $X$. citri subsp. citri and, in this study, it was also shown to produce a number of $X$. citri subsp. citri infection-induced fluorescent compounds, many of which are also detected in some of the other examined Citrus genotypes. A presumption could be made that these compounds are responsible for the low susceptibility of calamondin to $X$. citri subsp. citri. However, it is difficult to assign the responsibility of imparting the reduced susceptibility of calamondin to $\mathrm{CC}$ to any single example among these several induced compounds. For example, an intense fluorescent peak identified as scoparone appeared in X. citri subsp. citri-inoculated calamondin leaf tissue but no similarly intense peak was seen in control calamondin tissue (Table 2). The increased production of scoparone in related Citrus genotypes in response to the presence of other pathogens has been previously suggested to be a part of a general defense response in calamondin (Ortuño et al. 1997). However, a similar peak for scoparone also occurs in extracts of the $X$. citri subsp. citri-infected leaves of the highly susceptible lime, as well as in the $X$. citri subsp. citri-susceptible sweet orange, but not in the leaf extracts of $X$. citri subsp. citri-infected kumquat, which is equally or more tolerant than calamondin (Ference et al. 2019).

The fluorescent peak at $23.0 \mathrm{~min}$ (identified as herniarin) in $X$. citri subsp. citri-inoculated calamondin but not found in waterinjected calamondin samples occurred at very high intensities in both inoculated and noninoculated lime. Interestingly, this peak was higher in the water-injected than in the $X$. citri subsp. citriinoculated lime leaf extracts. Although the production of herniarin in calamondin seems to be induced by exposure to $X$. citri subsp. 
citri, its biosynthesis may be either directly inhibited by the pathogen in the more susceptible lime species or is metabolized after exposure to X. citri subsp. citri, or its accumulation is lost by the rapid destruction of tissue as a result of canker development, which is more severe in lime than in calamondin (Fig. 1). The constant concentration of limettin in both inoculated and noninoculated lime tissue suggests against the reduction of herniarin being due to the extensive destruction of tissue. XacPNP, a gene of $X$. citri subsp. citri encoding a plant natriuretic peptide-like protein, is capable of modifying host metabolism and is involved in the reduction of secondary metabolite production in infected citrus tissue as cellular resources are diverted down other pathways (Gottig et al. 2008). The influence of $X$. citri subsp. citri in lime tissue, possibly by means of XacPNP, may be involved in the reduced concentration of herniarin. Increased levels of herniarin were also detected in sweet orange at 21 DPI but with a mean peak intensity less than $9 \%$ of the mean peak intensity from calamondin at $21 \mathrm{DPI}$ and less than $0.6 \%$ of the mean peak intensity from lime at 21 DPI (Table 2). Although 21-DPI extracts from the more tolerant calamondin produced fluorescent peaks due to herniarin which were, on average, an order of magnitude greater than those produced by the more susceptible sweet orange, the herniarin fluorescent peaks from lime at 21 DPI were, on average, an order of magnitude greater than those produced by calamondin; thus, it is again difficult to unambiguously declare, based on our results, a direct role for this compound in inhibiting the growth of $X$. citri subsp. citri in the leaf tissue of less susceptible citrus. Among waterinjected controls, the majority of the identified compounds, as well as the unknown at $17.5 \mathrm{~min}$, were found to be most abundant in lime relative to the other Citrus genotypes. Among X. citri subsp. citri-inoculated samples at 21 DPI, again, most of the identified compounds were most abundant in lime, with the exceptions of tryptophan and auraptene, as well as the unidentified compound at 29.5 min. Tryptophan was found most abundantly in grapefruit, while the unknown compound at 29.5 min was found to be most abundant in sweet orange at 21 DPI. Levels of umbelliferone were similar in X. citri subsp. citri-inoculated lime and grapefruit, while levels of scoparone were similar in lime and sweet orange at 21 DPI. However, the difference in susceptibility to X. citri subsp. citri A306 between sweet orange, grapefruit, and lime is negligible (Ference et al. 2019). Auraptene, a coumarin known to reduce the Helicobacter pylori colonization of stomach lesions in gerbils, was highest in calamondin among the $X$. citri subsp. citri-inoculated group at 21 DPI (Takeda et al. 2007).

Though it is difficult to assign an inhibitory effect to any particular compound, our results also cannot definitively rule out a synergistic growth-inhibitory effect of multiple sets of these compounds in the different Citrus genotypes. However, it is important to note that, although many of these coumarins have been shown to exhibit antibacterial properties, the potencies of these compounds are extremely low, as shown from their typically very high minimum inhibitory concentration values (de Souza et al. 2005; Kayser and Kolodziej 1999; Ng et al. 1996).

Although the results of this study did not point out to us any newly formed compounds following $X$. citri subsp. citri inoculation that we could unambiguously attribute to Citrus genotype-specific susceptibility differences because the production of phenylpropanoids, in either character or quantity, did not directly correlate to susceptibility to $X$. citri subsp. citri, it remains perfectly plausible that there might still be undetected induced or constitutively expressed compounds able to limit the growth and virulence of the $X$. citri subsp. citri bacteria in leaves of less susceptible hosts. Antimicrobial properties of the phenylpropanoids in citrus leaves have been reported but, in general, the in vitro antibacterial strengths of these compounds are weak. Although this low antibacterial activity is also true for most of the coumarins and psoralens, in some instances these and similar compounds exert strong activities against different bacterial and fungal pathogens
(Céspedes et al. 2006; Yang et al. 2016). In unpublished in vitro trials, we have not observed any potent anti X. citri subsp. citri activity by the phenylpropanoids reported in Table 2 (data not shown). It is interesting however, that the two least susceptible genotypes, kumquat and calamondin, exhibited the highest levels of the dihydrochalcone $3^{\prime}, 5^{\prime}$-di- $C$-glucosyl phloretin, for which the aglycone portion of this compound, phloretin, exhibits powerful antibiotic actions in vitro. However, this compound did not respond to inoculation with $X$. citri subsp. citri (Barreca et al. 2014). Other similar dihydrochalcones also exhibit antibacterial effects (Awouafack et al. 2008; Hufford and Oguntimein 1980; Orjala et al. 1994). Although the various glucoside derivatives of phloretin have negligible antibacterial strength, microbial or endogenous plant deglycosidases may liberate the active aglycone at the point of contact with $X$. citri subsp. citri. However, whether there are any influences of $X$. citri subsp. citri infection on the biosynthesis of the aglycone and its glucosides remains unknown and additional detailed studies of Citrus leaf compounds and their changes following $X$. citri subsp. citri inoculation are needed.

\section{ACKNOWLEDGMENTS}

We thank V. Cook, T. Gottwald, G. McCollum, and X. Sun for their assistance.

\section{LITERATURE CITED}

Aldeek, F., Rosana, M. R., Hamilton, Z. K., Crosswhite, M. R., Burrows, C. W., Singh, S., Gerard, G., Hammack, W., and Cook, J. M. 2015. LC-MS/ MS method for the determination and quantitation of penicillin $\mathrm{G}$ and its metabolites in citrus fruits affected by huanglongbing. J. Agric. Food Chem. 63:5993-6000.

Armbruster, D. A., and Pry, T. 2008. Limit of blank, limit of detection and limit of quantitation. Clin. Biochem. Rev. 29:S49-S52.

Awouafack, M. D., Kouam, S. F., Hussain, H., Ngamga, D., Tane, P., Schulz, B., Green, I. R., and Krohn, K. 2008. Antimicrobial prenylated dihydrochalcones from Eriosema glomerata. Planta Med. 74:50-54.

Aziz, S. S. S. A., Sukari, M. A., Rahmani, M., Kitajima, M., Aimi, N., and Ahpandi, N. J. 2010. Coumarins from Murraua paniculata (Rutaceae). Malays. J. Anal. Sci. 14:1-5.

Barreca, D., Bellocco, E., Caristi, C., Leuzzi, U., and Gattuso, G. 2011. Flavonoid profile and radical-scavenging activity of Mediterranean sweet lemon (Citrus limetta Risso) juice. Food Chem. 129:417-422.

Barreca, D., Bellocco, E., Lagana, G., Ginestra, G., and Bisignano, C. 2014. Biochemical and antimicrobial activity of phloretin and its glycosilated derivatives present in apple and kumquat. Food Chem. 160:292-297.

Bock, C. H., Parker, P. E., and Gottwald, T. R. 2005. Effect of simulated winddriven rain on duration and distance of dispersal of Xanthomonas axonopodis pv. citri from canker-infected citrus trees. Plant Dis. 89:71-80.

Céspedes, C. L., Avila, J. G., Martinez, A., Serrato, B., Calderon-Mugica, J. C., and Salgado-Garciglia, R. 2006. Antifungal and antibacterial activities of Mexican tarragon (Tagetes lucida). J. Agric. Food Chem. 54:3521-3527.

Chen, P. S., Wang, L. Y., Chen, Y. J., Tzeng, K. C., Chang, S. C., Chung, K. R., and Lee, M. H. 2012. Understanding cellular defence in kumquat and calamondin to citrus canker caused by Xanthomonas citri subsp. citri. Physiol. Mol. Plant Pathol. 79:1-12.

Cueva, C., Moreno-Arribas, M. V., Martin-Alvarez, P. J., Bills, G., Vicente, M. F., Basilio, A., Rivas, C. L., Requena, T., Rodriguez, J. M., and Bartolome, B. 2010. Antimicrobial activity of phenolic acids against commensal, probiotic and pathogenic bacteria. Res. Microbiol. 161: 372-382.

Daglia, M. 2012. Polyphenols as antimicrobial agents. Curr. Opin. Biotechnol. 23:174-181.

del Rio, J., Gómez, P., Baidez, A., Arcas, M., Botia, J., and Ortuño, A. 2004. Changes in the levels of polymethoxyflavones and flavanones as part of the defense mechanism of Citrus sinensis (cv. Valencia late) fruits against Phytophthora citrophthora. J. Agric. Food Chem. 52:1913-1917.

de Souza, S. M., Delle Monache, F., and Smania, A., Jr. 2005. Antibacterial activity of coumarins. Z. Naturforsch. C 60:693-700.

Dopson, R. N. 1964. The eradication of citrus canker. Plant Dis. Rep. 48: 30-31.

Ference, C. M. 2016. The Production and Accumulation of Phenolic Compounds in Response to Infection by Xanthomonas citri subsp. citri in Leaves of Citrus Genotypes with Reduced Susceptibility to Citrus Canker. University of Florida, Gainesville, FL, U.S.A. 
Ference, C. M., Baldwin, E. A., Manthey, J. A., and Jones, J. B. 2019. Inhibitory extracts of calamondin leaves associated with precipitous decline of Xanthomonas citri subsp. citri populations. Eur. J. Plant Pathol. https:// doi.org/10.1007/s10658-019-01894-w.

Francis, M. I., Kostenyuk, I., Orbovic, V., Loskutov, A., Zolotukhin, M., and Graham, J. 2011. Automated needle-free injection method for delivery of bacterial suspensions into citrus leaf tissues. J. Phytopathol. 159:347-351.

Fu, X. Z., Gong, X. Q., Zhang, Y. X., Wang, Y., and Liu, J. H. 2012. Different transcriptional response to Xanthomonas citri subsp citri between kumquat and sweet orange with contrasting canker tolerance. PLoS One 7:e41790.

Gonçalves, D. R., Manthey, J. A., da Costa, P. I., Rodrigues, M. C. M., and Cesar, T. B. 2018. Analysis of fluorescence spectra of citrus polymethoxylated flavones and their incorporation into mammalian cells. J. Agric. Food Chem. 66:7531-7541.

Gottig, N., Garavaglia, B. S., Daurelio, L. D., Valentine, A., Gehring, C., Orellana, E. G., and Ottado, J. 2008. Xanthomonas axonopodis pv. citri uses a plant natriuretic peptide-like protein to modify host homeostasis. Proc. Natl. Acad. Sci. U.S.A. 105:18631-18636.

Gottwald, T., Graham, C., Bonn, G., Civerolo, E., Irey, M., Leite, R., Lopez, M., McCollum, G., Parker, P., Ramallo, J., Riley, T., Schubert, T., Stein, B., and Taylor, E. 2009. The epidemiological significance of postpackinghouse survival of Xanthomonas citri subsp. citri for dissemination of Asiatic citrus canker via infected fruit. Crop Prot. 28:508-524.

Gottwald, T. R., Bassanezi, R. B., Amorim, L., and Bergamin-Filho, A. 2007. Spatial pattern analysis of citrus canker-infected plantings in Sao Paulo, Brazil, and augmentation of infection elicited by the Asian leafminer. Phytopathology 97:674-683.

Gottwald, T. R., and Graham, J. H. 1992. A device for precise and nondisruptive stomatal inoculation of leaf tissue with bacterial pathogens. Phytopathology 82:930-935.

Graham, J. H., Gottwald, T. R., Cubero, J., and Achor, D. S. 2004. Xanthomonas axonopodis pv. citri: Factors affecting successful eradication of citrus canker. Mol. Plant Pathol. 5:1-15.

Graham, J. H., Gottwald, T. R., Riley, T. D., and Achor, D. 1992a. Penetration through leaf stomata and growth of strains of Xanthomonas campestris in citrus cultivars varying in susceptibility to bacterial diseases. Phytopathology 82:1319-1325.

Graham, J. H., Gottwald, T. R., Riley, T. D., and Bruce, M. A. 1992b. Susceptibility of citrus-fruit to bacterial spot and citrus canker. Phytopathology 82:452-457.

Hufford, C. D., and Oguntimein, B. O. 1980. Dihydrochalcones from Uvaria angolensis. Phytochemistry 19:2036-2038.

Imai, F., Kinoshita, T., and Sankawa, U. 1989. Constituents of the leaves of Murraya paniculata collected in Taiwan. Chem. Pharmocol. Bull. 37: 358-362.

Jagani, S., Chelikani, R., and Kim, D. S. 2009. Effects of phenol and natural phenolic compounds on biofilm formation by Pseudomonas aeruginosa. Biofouling 25:321-324.

Jiao, H. J., Wang, S. Y., and Civerolo, E. L. 1992. Enzymatic activities of citrus leaves from plants resistant and susceptible to citrus bacterial canker disease. Environ. Exp. Bot. 32:465-470.

Joshi, J. R., Burdman, S., Lipsky, A., and Yedidia, I. 2015. Effects of plant antimicrobial phenolic compounds on virulence of the genus Pectobacterium. Res. Microbiol. 166:535-545.

Kayser, O., and Kolodziej, H. 1999. Antibacterial activity of simple coumarins: Structural requirements for biological activity. Z. Naturforsch. C 54:169-174.

Khalaf, A., Moore, G. A., Jones, J. B., and Gmitter, F. G. 2007. New insights into the resistance of Nagami kumquat to canker disease. Physiol. Mol. Plant Pathol. 71:240-250.

Khalaf, A. A., Gmitter, F. G., Jr., Conesa, A., Dopazo, J., and Moore, G. A. 2011. Fortunella margarita transcriptional reprogramming triggered by Xanthomonas citri subsp. citri. BMC Plant Biol. 11:159.

Lattanzio, V., Lattanzio, V. M. T., and Cardinali, A. 2006. Role of phenolics in the resistance mechanisms of plants against fungal pathogens and insects.
Pages 23-67 in: Phytochemistry: Advances in Research. F. Imperato, ed. Research Signpost, Kerala, India.

Lee, H. A. 1918. Further data on the susceptibility of Rutaceous plants to citrus-canker. J. Agric. Res. 15:0661-0666.

Lee, H. A. 1921. The increase in resistance to citrus canker with the advance in maturity of citrus trees. Phytopathology 11:70-73.

Lou, S. N., and Ho, C. T. 2017. Phenolic compounds and biological activities of small-size citrus: Kumquat and calamondin. J. Food Drug Anal. 25:162-175.

Luthra, J. C., and Sattar, A. 1942. Citrus canker and its control in Punjab. Punjab Fruit J. 6:179-182.

Manthey, J. A., Grohmann, K., Berhow, M. A., and Tisserat, B. 2000. Changes in citrus leaf flavonoid concentrations resulting from blight-induced zincdeficiency. Plant Physiol. Biochem. 38:333-343.

Manthey, J. A., and Narciso, J. A. 2013. The HPLC-fluorescence detection of coumarins in 'Hamilin' sweet orange and 'Marsh' grapefruit leaf cankers. Proc. Fla. State Hortic. Soc. 126:217-219.

Ng, T. B., Ling, J. M., Wang, Z. T., Cai, J. N., and Xu, G. J. 1996. Examination of coumarins, flavonoids and polysaccharopeptide for antibacterial activity. Gen. Pharmacol. 27:1237-1240.

Ogawa, K., Kawasaki, A., Omura, M., Yoshida, T., Ikoma, Y., and Yano, M. 2001. 3',5'-Di-C-beta-glucopyranosylphloretin, a flavonoid characteristic of the genus Fortunella. Phytochemistry 57:737-742.

Orjala, J., Wright, A. D., Behrends, H., Folkers, G., Sticher, O., Ruegger, H., and Rali, T. 1994. Cytotoxic and antibacterial dihydrochalcones from Piper aduncum. J. Nat. Prod. 57:18-26.

Ortuño, A., Botía, J. M., Fuster, M. D., Porras, I., García-Lidón, A., and Del Río, J. A. 1997. Effect of scoparone (6,7-dimethoxycoumarin) biosynthesis on the resistance of tangelo Nova, Citrus paradisi, and Citrus aurantium fruits against Phytophthora parasitica. J. Agric. Food Chem. 45: 2740-2743.

Ortuño, A., Díaz, L., Alvarez, N., Porras, I., García-Lidón, A., and Del Río, J. A. 2011. Comparative study of flavonoid and scoparone accumulation in different Citrus species and their susceptibility to Penicillium digitatum. Food Chem. 125:232-239.

Rauha, J. P., Remes, S., Heinonen, M., Hopia, A., Kahkonen, M., Kujala, T., Pihlaja, K., Vuorela, H., and Vuorela, P. 2000. Antimicrobial effects of Finnish plant extracts containing flavonoids and other phenolic compounds. Int. J. Food Microbiol. 56:3-12.

Schubert, T. S., Rizvi, S. A., Sun, X., Gottwald, T. R., Graham, J. H., and Dixon, W. N. 2001. Meeting the challenge of eradicating citrus canker in Florida-Again. Plant Dis. 85:340-356.

Stanley, W. L., and Vannier, S. H. 1957. Chemical composition of lemon oil. I. Isolation of a series of substituted coumarins. J. Am. Chem. Soc. 79: 3488-3491.

Takeda, K., Utsunomiya, H., Kakiuchi, S., Okuno, Y., Oda, K., Inada, K., Tsutsumi, Y., Tanaka, T., and Kakudo, K. 2007. Citrus auraptene reduces Helicobacter pylori colonization of glandular stomach lesions in Mongolian gerbils. J. Oleo Sci. 56:253-260.

Tatum, J. H., and Berry, R. E. 1979. Coumarins and psoralens in grapefruit peel oil. Phytochemistry 18:500-502.

Treutter, D. 2006. Significance of flavonoids in plant resistance: A review. Environ. Chem. Lett. 4:147-157.

Wang, Y., Fu, X. Z., Liu, J. H., and Hong, N. 2011. Differential structure and physiological response to canker challenge between 'Meiwa' kumquat and 'Newhall' navel orange with contrasting resistance. Sci. Hortic. (Amsterdam) 128:115-123.

Wu, T. S. 1988. Coumarins from the leaves of Murraya paniculata. Phytochemistry 27:2357-2358.

Yang, L., Ding, W., Xu, Y., Wu, D., Li, S., Chen, J., and Guo, B. 2016. New insights into the antibacterial activity of hydroxycoumarins against Ralstonia solanacearum. Molecules 21:468.

Yu, M. W., Lou, S. N., Chiu, E. M., and Ho, C. T. 2013. Antioxidant activity and effective compounds of immature calamondin peel. Food Chem. 136: 1130-1135. 